Seção Livre

\title{
Ciência Baseada em Evidência? Resposta aos Comentários ao Artigo "Os Equívocos e Acertos da Campanha 'Náo à Medicalizaçáo da Vida"
}

Lincoln Frias ${ }^{\mathrm{I}}$

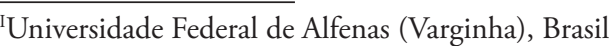

IIUniversidade Federal de Minas Gerais (Belo Horizonte), Brasil

Annelise Júlio-Costa ${ }^{\text {II }}$

Agradecemos muito a Rui Harayama e a Lygia Viégas, Jason Santos e Ariane Oliveira por comentarem nosso artigo. A identificação e o tratamento de crianças com transtornos de aprendizagem e Transtorno do Déficit de Atenção e Hiperatividade (TDAH) são questóes muito intrincadas e com repercussóes profundas em suas vidas. Por isso, é essencial que haja debate entre as diferentes perspectivas sobre o assunto.

Contudo, é lamentável que Viégas, Santos \& Oliveira (2013, p. 270) coloquem em dúvida a qualidade e honestidade do processo de editoração da Revista Pesquisa em Psicologia:

[...] qual a motivação dos autores para submeter um artigo construído com base em tantas confusóes e escolhas viciadas para realizar a discussão de tema tão sério e complexo? Com base em que critérios foram selecionados os pareceristas para avaliá-lo? Com base em que critérios os pareceristas aprovaram-no?É lamentável ainda mais porque as justificativas que apresentam para essas insinuaçóes são pequenas falhas na apresentação da filiação institucional da campanha "Contra a Medicalização da Vida" e sua insatisfação com nossa estratégia de nos concentrar nos documentos de divulgação da campanha. Comecemos por esse último ponto.

Tanto Harayama (2013) quanto Viégas, Santos \& Oliveira (2013) sugerem que favorecemos nossa perspectiva ao buscar os argumentos contrários à medicalização em textos para o público leigo, ao passo que utilizamos a literatura científica em nossa resposta a eles. Diz Harayama (2013, p. 263):

Não entrarei no mérito da forma como os autores selecionaram os trechos desse texto, e nem a predileção por textos-manifestos em detrimento da revisão bibliográfica de publicaçóes científicas minhas e de outros membros do Fórum. Como antropólogo, que dá preferência ao discurso nativo e do "outro", fico feliz por ver um texto de vulgarização de um movimento político sendo citado como produção científica que, nos termos dos autores, "compreende mal a ciência".

Por sua vez, Viégas, Santos \& Oliveira (2013, p. 269) afirmam que "o artigo focaliza apenas folhetos produzidos para ampliar a popularização do debate no meio social. Nesse sentido, a análise fica claramente desigual, aspecto que náo pode ser considerado como característica de rigor científico."

A justificativa para nossa escolha é simples: focamos os panfletos da campanha porque acreditamos que eles desempenham o papel mais decisivo na discussão pública sobre o assunto. Aliás, essa também é a opinião dos defensores dela. Harayama (2013, p. 262) afirma em seu comentário:

Se a literatura internacional vem denunciando os processos de medicalização e a cooptação da academia e dos profissionais da saúde pela indústria farmacêutica (Abadie, 2010; Light, 2010; Shah, 2006), no Brasil, é com certeza a atuação político-acadêmica dos membros do Fórum que tem pautado outros setores e grupos nacionais que têm forte ligação com a indústria farmacêutica.

Ora, se são os panfletos que têm mais influência, são eles que merecem resposta. Além disso, como dizem os próprios Viégas, Santos \& Oliveira (2013, p. 269) em seu comentário:

[...] cada um desses folhetos se origina de discussóes profundas, por vezes 
produzidas pelos mesmos autores de artigos e capítulos de livros científicos e acadêmicos. Há de se ressaltar o esforço que a produção de tais panfletos envolve, considerando o hábito de seus autores em ter como interlocutores seus pares acadêmicos, e a necessidade de se tornar a linguagem mais acessível, sem, com isso, simplificar as ideias contidas em cada um desses materiais.

Nossa estratégia de analisar os folhetos e não os artigos seria ilegítima (ou anticientífica, como apontou Harayama (2013), ou não séria, como sugerem Viégas, Santos \& Oliveira (2013) se a literatura científica que critica a medicalização contivesse bons argumentos que não aparecem nos panfletos e que não incluímos em nossa análise. Podemos estar errados, mas em nossa pesquisa não os encontramos.

Como críticos da medicalização, Harayama (2013) e Viégas, Santos e Oliveira (2013) certamente estavam muito mais capacitados para identificá-los. $\mathrm{O}$ fato de que não tenham apresentado nenhum argumento novo em seus comentários (ainda que Viégas, Santos e Oliveira (2013) tenham apresentado novos elementos em defesa dos mesmos argumentos que criticamos) sugere que nossa estratégia foi bem sucedida:identificamos os melhores argumentos contra a medicalização dos transtornos de aprendizagem e TDAH. Portanto, continuamos acreditando que não foi inadequado focar os panfletos.

Nosso artigo poderia ter sido melhor em termos de detalhe - é sempre possível escrever um texto com mais nuances e mais referências. Mas não deixamos de lado nenhum argumento central. É natural que os defensores desses argumentos considerem que eles podem ser melhor defendidos. Artigos servem para movimentar a discussão, não para encerrar o debate. Isso faz parte da discussão científica, não é um motivo para desqualificar o trabalho de autores, editores e pareceristas.

Antes de prosseguir, gostaríamos de reconhecer e lamentar um equívoco que cometemos e que foi apontado pelos dois comentários. Ao contrário do que dissemos, o Fórum sobre Medicalização da Educação e da Sociedade não é um movimento comandado pelo Conselho Federal de Psicologia. O Fórum é formado por diversos setores e é ele quem estimula a discussão da medicalização nos conselhos profissionais, na academia etc. Além disso, erramos ao atribuir um trecho de um texto de Harayama a outro autor.
Indo às críticas mais substanciais, comecemos pelo comentário de Harayama (2013). Nossa opinião é que o comentário dele náo traz argumentos nem elementos novos que nos façam modificar nossas conclusóes ou rever as análises que realizamos dos argumentos da campanha "Não à medicalização da vida". O que ele fez foi apenas sugerir que há "vícios de dados e metodologia", mas, ao menos a nosso ver, não justificou essa afirmativa.

As duas observações mais sérias feitas por Harayama (2013) em seu comentário a nosso artigo tratam da indústria farmacêutica e da relação entre ciência e religião. Vejamos cada um deles separadamente.

De acordo com ele, o fato de que o lobby da indústria farmacêutica nos EUA tenha derrubado a proibição dos anúncios de medicamentos mostra que "é preciso discordar veementemente" da seguinte afirmação que fizemos em nosso artigo: o fato de que a indústria farmacêutica lucra com o aumento da demanda de algum medicamento não necessariamente significa que o medicamento seja ruim para os usuários e que a demanda seja criada pela indústria. Não nos parece que aquele fato seja suficiente para mostrar que nossa afirmação está equivocada. $\mathrm{E}$ a definição de medicalização que ele oferece no parágrafo seguinte também não é suficiente para atingir esse objetivo. Portanto, náo vemos motivo para mudar o que afirmamos na seção $O$ Argumento da Pressão da Indústria e a Presunção Contra Psicofármacos de nosso artigo.

Harayama (2013) e Viégas, Santos e Oliveira (2013) nos convenceriam de que há medicalização no sentido pejorativo se apresentassem estudos mostrando que os tratamentos farmacêuticos para esses transtornos são inúteis ou que seus benefícios aos pacientes náo compensam os prejuízos que podem lhes causar. Mas não fizeram isso.

Apesar das palavras fortes que empregaram e das citações de autores feitas na seção 4 de Viégas, Santos e Oliveira (2013), nenhuma evidência foi demonstrada. Náo basta dizer que tal ou qual autor acha que o diagnóstico é impreciso, nem citar a cautela da bula da Ritalina como argumento a seu favor, é preciso discutir os resultados empíricos. Apenas como ilustração, uma revisão do banco de dados SciELO (www.scielo.org), no dia 19 de outubro de 2013, mostrou que, em uma busca de textos com o indicativo "medicalização", são levantados 157 artigos. Quando incluímos na busca a palavra "escola", somente nove artigos são listados. Após a leitura de todos 
os resumos dos textos listados pelas buscas, não foi encontrado nenhum que contenha teste de hipótese demonstrando a não eficácia dos medicamentos.

Osegundo comentário substantivo deHarayama (2013, p. 263) consiste em reafirmar que a ciência é a religião do século XXI e dizer que distorcemos essa sua analogia. Segundo ele, a separação entre religiáo e ciência é "borrada" porque alguns religiosos na história brasileira tomavam decisões baseadas em argumentos e evidências, tal como a ciência, e porque atualmente as pessoas acreditam que "a comprovação científica tem equivalência com a providência divina de outrora" - o comentário de Viégas, Santos e Oliveira (2013) contém uma afirmação semelhante.

Contudo, as referidas semelhanças não impedem a existência das diferenças que apontamos em nosso artigo:

[...] o discurso religioso é baseado em verdades reveladas, enquanto que a ciência baseia-se em experimentos empíricos controlados; a religião é baseada em dogmas, afirmaçôes inquestionáveis, enquanto que a ciência é baseada na exigência de transparência sobre os dados, na revisão por pares e na crítica mútua; a religião é baseada em acontecimentos sobrenaturais, enquanto que a ciência exige replicação dos resultados; por fim, a religião baseiase na fé, na disposição de acreditar mesmo na ausência de evidências, enquanto que a ciência pauta-se pela racionalidade, entendida como a procura por evidências para sustentar afirmaçóes (Frias \& Júlio-Costa, 2013, p. 5 - baseado em Ferngren, 2002).

Assim, não nos parece que Harayama (2013) tenha dado motivos para justificar a afirmaçáo de que distorcemos sua opiniáo e nem para que mudemos nossa crítica no que se refere à aproximação entre ciência e religião.

Viégas, Santos e Oliveira (2013, p. 272) afirmam sobre a dislexia e o TDAH que "sem comprovação científica, estamos diante de 'doenças da moda', que silenciam sobre a complexidade envolvida no processo de desenvolvimento e aprendizagem, e sua inter-relação com a escolarização."

Mas um dos objetivos de Frias e Júlio-Costa (2013) foi exatamente apontar as principais evidências sobre a validade nosológica dos transtornos. Citando um trecho sobre TDAH:

Com relação à estabilidade do TDAH ao longo do ciclo vital, estima-se que cerca de dois terços dos sujeitos que apresentam o diagnóstico na infância também persistam com o transtorno na idade adulta (Spencer, Biederman \& Mick, 2007). Em uma série de estudos recentes sobre o desenvolvimento cerebral de crianças com TDAH, Shaw et al. (2009; 2011) verificaram que embora o curso estrutural do desenvolvimento neural de crianças e adolescentes com TDAH e crianças sem transtornos do desenvolvimento seja muito semelhante, há diferenças substanciais na velocidade de maturação dos circuitos cerebrais entre os dois grupos. Tais diferenças são particularmente pronunciadas em relação ao córtex pré-frontal que se desenvolve mais tardiamente em crianças e adolescentes com TDAH. O TDAH, assim como a dislexia, tem sido estudado ao longo do último século, e existem tanto dados comportamentais (Willcutt et al., 2012), quanto neurobiológicos sobre o transtorno (Cortese et al., 2012). Uma série de características cognitivas e comportamentais tem sido apontada de forma consistente como presente em indivíduos como TDAH, tais como déficits nas funçôes executivas (Barkley, 2012), aversão ao atraso (Sonuga-Barke, Sergeant, Nigg \& Willcutt, 2008), dificuldades em postergar recompensas (Scheres, Tontsch \& Lee Thoeny, 2013) e diminuição na velocidade de processamento de informação (McGrath et al., 2011). Existem também estudos genéticos que mostram que a herdabilidade do TDAH é da ordem de 0,75 (Goldstein, 2003). (Frias \& Júlio-Costa, 2013, p. 8). [Mais informaçóes sobre o transtorno estão descritas em nosso artigo.]

Viégas, Santos e Oliveira (2013, p. 273) criticam o fato de nos referirmos às crianças com TDAH ou dislexia como pacientes: 
Para nós seria suficiente apontar a contradição de tais afirmações pelo simples fato de que a criança ou adolescente, que na escola devem ser vistos e tratados como alunos, são chamados pela alcunha de "paciente", estigma de doente que certamente os acompanha e acompanhará na vida escolar.

Entretanto, é muito simplório pensar que a escola deve tratar as crianças apenas como alunos. Mesmo que a função primordial da escola seja ensinar, é preciso entender o indivíduo em uma dimensão mais ampla e tentar ajudá-lo em suas necessidades. Em relação ao estigma, mantemos a análise que fizemos em nosso artigo, na seção intitulada $\mathrm{O}$ Argumento da Estigmatização.

Ainda foram apontadas outras críticas sobre o nosso artigo, tais como os malefícios dos medicamentos, a precisão do diagnóstico e a falta de marcadores biológicos. Entretanto, como esses temas foram amplamente discutidos em nosso artigo e nenhuma nova evidência foi trazida por Harayama (2013) e Viégas, Santos e Oliveira (2013), não vemos razão em retomar a discussão.

Para além da polêmica, acreditamos que o debate, a busca por evidências científicas e a formação de bons profissionais são cruciais para o avanço da discussáo. Mas, acima de tudo, o progresso científico deve ter como propósito a melhora da qualidade de vida das crianças, incluindo modificaçôes das políticas públicas que ajudem a atingir esse objetivo.

Por fim, agradecemos a todo o corpo editorial da revista Psicologia em Pesquisa, na pessoa do professor doutor Saulo de Freitas Araujo (editor-chefe), que, desde o momento da submissão do artigo, se posicionou de maneira ética, séria e solícita.

\section{Referências}

Frias, L., \& Júlio-Costa, A. (2013). Os Equívocos e Acertos da Campanha "Não à Medicalização da Vida”. Psicologia em Pesquisa, 7(1), 3-12.

Harayama, R. M. (2013). Os movimentos sociais, a ciência, a medicalização e a antropologia: comentário sobre o artigo "Os equívocos e acertos da Campanha "Não à medicalização da vida". Psicologia em Pesquisa, 7(2), 261-265.
Viégas, L. S., Gomes, J., \& Oliveira, A. R. F. (2013). Os equívocos do artigo "Os equívocos e acertos da campanha 'não à medicalizaçáo da vida'”. Psicologia em Pesquisa, 7(2), 266-276.

\section{Endereço para correspondência:}

Avenida Celina Ferreira Ottoni, 4.000 - Padre Vitor CEP 37048-395 - Varginha/MG

E-mail: lincolnfrias@gmail.com 